\title{
A FUZZY MODELING APPROACH TO EVALUATE FACULTY PERFORMANCE
}

\author{
A.Neogi, A.C. Mondal, S.K. Mandal \\ ${ }^{a}$ Lecturer, Advanced Institute of Modern Management \& Technology (affli. W.B. \\ University of Technology), 55, Barrack Road, Barrackpore, Kolkata-700120, Postal Address: \\ 3,Shyamaprasad Road, P.O. Nabagram, Hooghly, PIN-712246, West Bengal, Phone:91-33-26739725, \\ Mobile:9433910251, email:amartyaneogi@gmail.com \\ ${ }^{\mathrm{b}}$ Reader \& Head of Deptt., Department of Computer Science, The University of \\ Burdwan, Golapbag , Burdwan-713104, West Bengal, INDIA, Phone: 9434386968, email: \\ abhoy mondal@yahoo.co.in \\ 'Assistant Professor, National Institute of Technical Teachers' Training \& \\ Research(Ministry of HRD, Govt. of India), Block-FC, Sector-III, Salt Lake City, Kolkata-700106, \\ Phone:9830490061, email:mandal_soumitra@yahoo.com
}

\begin{abstract}
Performance of a teacher is vital both for students and institution and must be measured and evaluated for positive reinforcement to teaching. This paper presents a mathematical model to evaluate faculty's teaching performance using fuzzy logic In this proposed evaluation the degree of satisfaction is defined in advance by experts with respect to levels of performance. Evaluator awards fuzzy marks into the fuzzy performance sheet according to each level of performance. From this, the degree of satisfaction of a subject topic is calculated and the result is calculated based on all the topics in the subject. The obtained results from the proposed approach are compared with the conventional non-fuzzy approach and the comparative results are presented.
\end{abstract}

Keywords: Fuzzy performance sheet, Fuzzy set, Linguistic term, faculty’s teaching performance.

\section{INTRODUCTION}

Educational institutions are organizations which strongly need to have a performance management system for continuing to supply good quality students to today's competitive environment and, in those organizations faculty of the school are the people who directly contact, educate and contribute to students' higher knowledge. Thus, performance of a faculty is vital both for students and institution, and must be measured and evaluated for positive reinforcement to faculty. Evaluation of a faculty is a difficult and sensitive issue which has quantitative and qualitative aspects, complexity and imprecision.

Traditional methods of faculty performance evaluation have been presented in [1-4]. In the problem of faculty performance evaluation, the evaluation attributes are generally multiple. Also, since the judgments from experts are usually vague rather than crisp, a judgment should be expressed by using fuzzy sets which has the capability of representing vague data. There are few papers handling fuzzy sets and a multiattribute method together for the performance evaluation [5-6].

This paper is organized as follows: The following section proposes the fuzzy based [7] faculty evaluation method with Block diagram. In the third section, the proposed fuzzy Mathematical modeling [8] are given in detail. The fourth section explains the proposed fuzzy modeling with a suitable Case study. In the fifth section, the fuzzy performance evaluation result is compared with the non-fuzzy evaluation approach. Finally, the conclusion remarks are given.

\section{FUZZY FACULTY EVALUATION}


Fig. 1 shows the structure of a faculty evaluation method. The factors considered by the model as input parameters are evaluator's satisfaction level, allotted marks to topics and instruction given parameter. The output produced from the model is total marks and/or faculties rating.

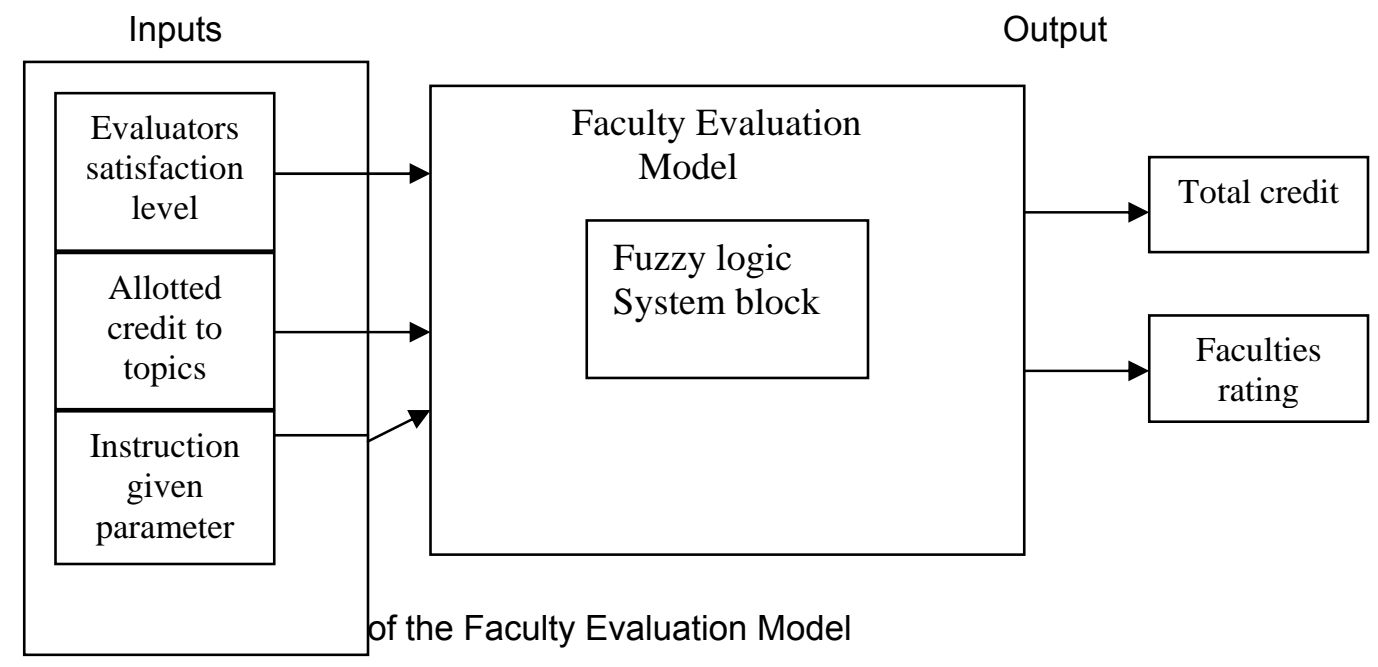

\section{FUZZY MATHEMATICAL MODELING}

Let there are ten satisfaction levels to evaluate the faculties teaching quality. They are $E$ (excellent), VG(very good), G(good), MG(more or less good), F(fair), MB(more or less bad), B(bad), VB(very bad), VVB(very very bad) and $E B($ extremely bad). The degrees of the satisfaction levels are shown in the following table:

Tab 1: Degrees of satisfaction according to performance level

\begin{tabular}{|c|c|c|}
\hline $\begin{array}{c}\text { Satisfaction } \\
\text { levels }\end{array}$ & Degrees of satisfaction & $\begin{array}{c}\text { Maximum degree of } \\
\text { satisfaction }\end{array}$ \\
\hline E & $91-100 \%$ & 1.00 \\
\hline VG & $81 \%-90 \%$ & 0.90 \\
\hline G & $71 \%-80 \%$ & 0.80 \\
\hline MG & $61 \%-70 \%$ & 0.70 \\
\hline F & $51 \%-60 \%$ & 0.60 \\
\hline MB & $41 \%-50 \%$ & 0.50 \\
\hline B & $25 \%-40 \%$ & 0.40 \\
\hline VB & $10 \%-24 \%$ & 0.24 \\
\hline VVB & $1 \%-9 \%$ & 0.09 \\
\hline EB & $0 \%$ & 0.00 \\
\hline
\end{tabular}

Let $\mathrm{K}$ be a set of satisfaction levels, where $\mathrm{K}=\{\mathrm{E}, \mathrm{VG}, \mathrm{G}, \mathrm{MG}, \mathrm{F}, \mathrm{MB}, \mathrm{B}, \mathrm{VB}, \mathrm{VVB}, \mathrm{EB}\}$ and assume $\mathrm{H}$ be a mapping function which maps a satisfaction level to the maximum degree of satisfaction of the corresponding satisfaction level, where $\mathrm{H}: \mathrm{K}->[0,1]$. From the above table,

$H($ Excellent $)=1.0$ i.e., $H(E)=1.0$. Similarly,

$H(V G)=0.90, H(G)=0.80, H(M G)=0.70, H(F)=0.60, H(M B)=0.50, H(B)=0.40, H(V B)=0.24, H(V V B)=0.09$, $H(E B)=0$.

So, in the proposed method, the degrees of satisfaction is defined in advance with respect to levels of performance and from which the maximum degree of satisfaction per level is obtained. 
Here, a fuzzy performance sheet which is a matrix type structure containing twelve columns and $\mathrm{n}$ rows where $\mathrm{n}$ is the total number of topics in a subject is used to evaluate faculties performance. Below table is a fuzzy performance sheet:

Tab 2: Example of a fuzzy performance sheet

\begin{tabular}{|c|c|c|c|c|c|c|c|c|c|c|c|}
\hline $\begin{array}{c}\text { Topic } \\
\text { No. }\end{array}$ & \multicolumn{9}{|c|}{ Satisfaction level } & $\begin{array}{c}\text { Degree of } \\
\text { satisfaction }\end{array}$ \\
\cline { 2 - 13 } & $\mathrm{E}$ & VG & G & MG & F & MB & B & VB & VVB & EB & \\
\hline $\mathrm{T}_{1}$ & 0.8 & .6 & .9 & .1 & 0 & 0 & 0 & 0 & 0 & 0 & \\
\hline $\mathrm{T}_{2}$ & & & & & & & & & & & \\
\hline.. &.. &.. &.. &.. &.. &.. &.. &.. &.. &.. & $\ldots$ \\
\hline $\mathrm{T}_{\mathrm{n}}$ & & & & & & & & & & & Total marks $=$ \\
\hline
\end{tabular}

At the bottom of the sheet there is a box which tells the total marks. The first column reveals the serial numbers of the topic, in any row, the columns from the seconds to the eleventh shows the fuzzy mark awarded to the answer of the corresponding topic in the first column, where the fuzzy mark is represented as a fuzzy set in the universe of discourse $\mathrm{K}$. The last column shows the degree of satisfaction evaluated by the proposed method awarded to each topic. The box at the bottom shows the total marks awarded to a faculty.

From the above table, the satisfaction level regarding the first topic is represented by a fuzzy set $F\left(T_{1}\right)$ which is

$\begin{aligned} F\left(T_{1}\right)= & \{(E, 0.8),(V G, 1),(G, 0.5),(M G, 0.1),(F, 0),(M B, 0),(B, 0),(V B, 0),(V V B, 0),(E B, 0)\} \\ & =\{(E, 0.8),(V G, 1),(G, 0.5),(M G, 0.1)\}\end{aligned}$

It indicates that the satisfaction level of the faculty's lecture quality with respect to the first topic is defined as $80 \%$ excellent, $100 \%$ very good, $50 \%$ good and $10 \%$ medium good. The proposed algorithm is explained by the following steps as given below:

Step 1: Let that the fuzzy mark of the topic $T_{i}$ of a faculty's performance evaluated by an evaluator is shown in below table:

Tab 3: Fuzzy marks of topic $T_{i}$ in a fuzzy performance sheet

\begin{tabular}{|c|c|c|c|c|c|c|c|c|c|c|c|}
\hline \multirow{2}{*}{$\begin{array}{l}\text { Topic } \\
\text { No. }\end{array}$} & \multicolumn{10}{|c|}{ Satisfaction level } & \multirow{2}{*}{$\begin{array}{c}\text { Degree of } \\
\text { satisfaction }\end{array}$} \\
\hline & $E$ & VG & $\mathrm{G}$ & $\overline{M G}$ & $\mathrm{~F}$ & MB & $B$ & VB & VVB & EB & \\
\hline $\mathrm{T}_{1}$ & 0.7 & .9 & .6 & 2 & 0 & 0 & 0 & 0 & 0 & 0 & \\
\hline & & .. & .. & .. &. & .. & .. & & & &.. \\
\hline $\mathrm{T}_{\mathrm{i}}$ & $\mathrm{y}_{1}$ & $\mathrm{y}_{2}$ & $y_{3}$ & $\mathrm{y}_{4}$ & $\mathrm{y}_{5}$ & $\mathrm{y}_{6}$ & $y_{7}$ & $\mathrm{y}_{8}$ & $y_{9}$ & $\mathrm{y}_{10}$ & $\ldots$ \\
\hline ... & .. &.$\cdot$ & $\cdot$. & .. & .. & .. &.. & .. & .. & .. & Total marks= \\
\hline
\end{tabular}

Here $y_{i} \in[0,1]$ which is the membership values awarded to each level of performance and $1 \leq i \leq 10 . F\left(y_{i}\right)$ is the respective maximum degree of satisfaction. Now the degree of satisfaction $D\left(T_{i}\right)$ of the $T_{i}$ topic of the faculty's performance can be evaluated by the function $D$ as

$$
\begin{aligned}
D\left(T_{i}\right)= & \frac{\sum T_{i}\left(y_{i}\right) \times F\left(y_{i}\right)}{\sum T_{i}\left(y_{i}\right)} \\
& =\underline{y}_{1} \underline{x H(E)+y_{2}} \frac{x H(V G)+\ldots+\ldots+y_{10}}{y_{1}+y_{2}+\ldots+y_{10}} \underline{H(E B)}
\end{aligned}
$$

where $D\left(T_{i}\right) \in[0,1]$. 
Step 2: Assume that faculty's performance marks to a subject consists of 100 marks. Let, that in total there are $\mathrm{n}$ number of topics to be covered.

Total marks $=100$

$\mathrm{T}_{1}$ carries $\mathrm{CM}_{1}$ marks

$\mathrm{T}_{2}$ carries $\mathrm{CM}_{2}$ marks

..... $\quad$... n

$T_{n}$ carries $C_{n}$ marks where $\sum \mathrm{CM}_{i}=100$

$\mathrm{i}=1$

Let, that the evaluated degree of satisfaction of the topic $T_{1}, T_{2}, . .$, and $T_{i}$ are $D\left(T_{1}\right), D\left(T_{2}\right), \ldots$, and $D\left(T_{n}\right)$ respectively, then the total marks (TM) of the faculty can be evaluated as follows:

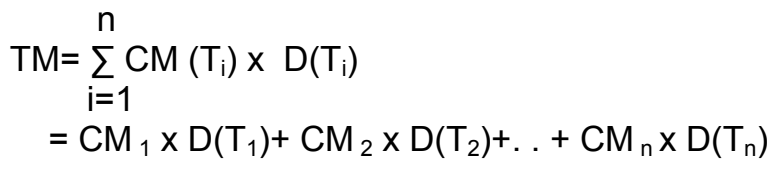

Here, CM $\left(T_{i}\right)$ is the marks allocated for each topic by the evaluator and $D\left(T_{i}\right)$ is the calculated degrees of satisfaction for $T_{i}$.

Show this total marks in the appropriate box at the bottom of the fuzzy performance sheet.

Step 3: Construct a generalized fuzzy evaluation method.

Assume that evaluator evaluated the faculty's performance score using the following criteria as given below:

$I_{1}$ : teaching attitude, $I_{2}$ : teaching plan, $I_{3}$ : teaching skill, $I_{4}$ : independent idea generation, $I_{5}$ : speech clarity, $I_{6}$ : topic presentation, $I_{7}$ : topic clarity, $I_{8}$ : friendliness, $I_{9}$ : concept, $I_{10}$ : vocabulary etc.

Criteria based parameters are related with different disciplines and related papers/subjects within it.

Tab 4: Generalized fuzzy performance sheet

\begin{tabular}{|c|c|c|c|c|c|c|c|c|c|c|c|c|c|}
\hline \multirow{2}{*}{$\begin{array}{c}\text { Topic } \\
\text { No. }\end{array}$} & \multirow{2}{*}{$\begin{array}{l}\text { Instruction } \\
\text { parameter }\end{array}$} & \multicolumn{10}{|c|}{ Satisfaction level } & \multirow{2}{*}{$\begin{array}{c}\text { Degree of } \\
\text { satisfaction } \\
\text { for criteria }\end{array}$} & \multirow{2}{*}{$\begin{array}{l}\text { Degree of } \\
\text { satisfaction } \\
\text { for topic }\end{array}$} \\
\hline & & \multicolumn{10}{|c|}{ 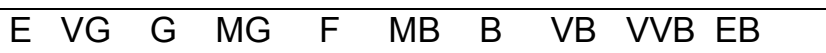 } & & \\
\hline \multirow[t]{6}{*}{$\mathrm{T}_{1}$} & \multirow{6}{*}{$\begin{array}{l}l_{1} \\
I_{2} \\
I_{3} \\
l_{4}\end{array}$} & & & & & & & & & & & $\mathrm{D}\left(\mathrm{I}_{11}\right)$ & \multirow[t]{6}{*}{$\mathrm{P}\left(\mathrm{I}_{1}\right)$} \\
\hline & & & & & & & & & & & & $\mathrm{D}\left(\mathrm{I}_{12}\right)$ & \\
\hline & & & & & & & & & & & & $\mathrm{D}\left(\mathrm{I}_{13}\right)$ & \\
\hline & & & & & & & & & & & & $\mathrm{D}\left(\mathrm{I}_{14}\right)$ & \\
\hline & & .. & .. & .. & .. & .. & $\ldots$ & .. &.. & .. & .. & & \\
\hline & & & & & & & & & & & & $\mathrm{D}\left(\mathrm{I}_{1 \mathrm{~m}}\right)$ & \\
\hline \multirow[t]{6}{*}{$\mathrm{T}_{2}$} & \multirow{6}{*}{$\begin{array}{l}\mathrm{I}_{1} \\
\mathrm{I}_{2} \\
\mathrm{I}_{3} \\
\mathrm{I}_{4}\end{array}$} & & & & & & & & & & & $\mathrm{D}\left(\mathrm{I}_{21}\right)$ & \multirow[t]{6}{*}{$\mathrm{P}\left(\mathrm{I}_{2}\right)$} \\
\hline & & & & & & & & & & & & $\mathrm{D}\left(\mathrm{I}_{22}\right)$ & \\
\hline & & & & & & & & & & & & $\mathrm{D}\left(\mathrm{I}_{23}\right)$ & \\
\hline & & & & & & & & & & & & $\mathrm{D}\left(\mathrm{I}_{24}\right)$ & \\
\hline & & .. & .. & .. & ... & .. & .. &.. & .. & ... & .. &.. & \\
\hline & & & & & & & & & & & & $\mathrm{D}\left(\mathrm{I}_{2 \mathrm{~m}}\right)$ & \\
\hline$\ldots$ & $\ldots$ & .. & .. & .. & .. & .. & .. &.. & .. & .. & .. & .. & \multirow{7}{*}{$P\left(I_{n}\right)$} \\
\hline \multirow[t]{6}{*}{$\mathrm{T}_{\mathrm{n}}$} & \multirow{6}{*}{$\begin{array}{l}\mathrm{l}_{1} \\
\mathrm{I}_{2} \\
\mathrm{I}_{3} \\
\mathrm{l}_{4}\end{array}$} & & & & & & & & & & & $\mathrm{D}\left(\mathrm{I}_{\mathrm{n} 1}\right)$ & \\
\hline & & & & & & & & & & & & $\mathrm{D}\left(\mathrm{I}_{\mathrm{n} 2}\right)$ & \\
\hline & & & & & & & & & & & & $\mathrm{D}\left(\mathrm{I}_{\mathrm{n} 3}\right)$ & \\
\hline & & & & & & & & & & & & $\mathrm{D}\left(\mathrm{I}_{\mathrm{n} 4}\right)$ & \\
\hline & & .. & .. &.. & .. & .. & ... &.. &.. & .. & .. &.. & \\
\hline & & & & & & & & & & & & $\mathrm{D}\left(\mathrm{I}_{\mathrm{nm}}\right)$ & \\
\hline
\end{tabular}


Total marks $=\mathrm{CM}_{1} \times \mathrm{P}\left(\mathrm{I}_{1}\right)+\mathrm{CM}_{2} \times \mathrm{P}\left(\mathrm{I}_{2}\right)+. .+\mathrm{CM}_{\mathrm{n}} \times \mathrm{P}\left(\mathrm{I}_{\mathrm{n}}\right)$

Assume that the weights of the instruction parameter $I_{1}, I_{2}, I_{3}, l_{4}$ and $I_{n}$ are $w_{1}, w_{2}, w_{3}, w_{4} \ldots w_{n}$ respectively, where $w_{i} \in[0,1]$ and $1 \leq i \leq 4$. Also assume that an evaluator can evaluate each topic of a faculty's performance score sheet using the above four instruction parameter. It evaluates the faculty's performance using the proposed method as shown in the above table where the degrees of satisfaction of topic $T_{i}$ of a faculty's performance score in respect to the parameter $I_{1}, I_{2}, I_{3}, I_{4} \ldots I_{m}$ evaluated by the method are $D\left(l_{i 1}\right)$, $D\left(I_{i 2}\right) D\left(I_{i 3}\right) D\left(l_{i 4}\right) \ldots D\left(I_{\text {im }}\right)$ respectively where $0 \leq D\left(I_{\text {im }}\right) \leq 1$.

The degree of satisfaction $P\left(\mathrm{I}_{i}\right)$ of the topic $T_{i}$ of the faculty's performance sheet can be evaluated as:

$P\left(T_{i}\right)=w_{1} \times D\left(I_{i 1}\right)+w_{2} \times D\left(l_{i 2}\right)+\ldots+w_{4} \times D\left(I_{i 4}\right)+\ldots+w_{n} \times D\left(I_{\text {im }}\right)$

$$
\mathrm{w}_{1}+\mathrm{w}_{2}+\ldots+\mathrm{w}_{4}+\ldots+\mathrm{w}_{\mathrm{n}}
$$

where $P\left(T_{i}\right) \in[0,1]$ and $0 \leq i \leq n$. The total marks of the faculty can be evaluated and is equal to $\mathrm{CM}_{1} \times \mathrm{P}\left(\mathrm{T}_{1}\right)+\mathrm{CM}_{2} \times \mathrm{P}\left(\mathrm{T}_{2}\right)+\ldots+\mathrm{CM}_{\mathrm{n}} \times \mathrm{P}\left(\mathrm{T}_{\mathrm{n}}\right)$. Apply this formula to calculate the total marks in the appropriate box at the bottom of the fuzzy performance sheet.

\section{CASE STUDY}

Consider a faculty's performance sheet to a subject consists of 100 marks. Let that in total there are four topics to be covered.

TOTAL MARKS $=100$

$T_{1}$ carries 10 marks, $T_{2}$ carries 25 marks, $T_{3}$ carries 30 marks and $T_{4}$ carries 35 marks.

The case study has been executed based on only four parameters such as:- $I_{1}, I_{2}, I_{3}, I_{4}$. Evaluator evaluates the topics based on these four instruction parameter as given below:

$\mathrm{I}_{1}$ : teaching attitude,

$\mathrm{I}_{2}$ : teaching plan,

$\mathrm{I}_{3}$ : teaching skill,

$\mathrm{I}_{4}$ : independent idea generation.

Let that an evaluator evaluates a faculty's performance by generalized fuzzy performance sheet as shown in below table:

Tab 5: An example of fuzzy performance sheet

\begin{tabular}{|c|c|c|c|c|c|c|c|c|c|c|c|c|c|}
\hline \multirow{2}{*}{$\begin{array}{l}\text { Topic } \\
\text { No. }\end{array}$} & \multirow{2}{*}{$\begin{array}{c}\text { Inst. } \\
\text { paramete } \\
r\end{array}$} & \multicolumn{10}{|c|}{ Satisfaction level } & \multirow{2}{*}{$\begin{array}{c}\text { Degree of } \\
\text { satisfaction } \\
\text { for criteria }\end{array}$} & \multirow{2}{*}{$\begin{array}{l}\text { Degree of } \\
\text { satisfactio } \\
\mathrm{n} \text { for topic }\end{array}$} \\
\hline & & $E$ & VG & G & MG & $\mathrm{F}$ & $\mathrm{MB}$ & $B$ & VB & & & & \\
\hline \multirow[t]{4}{*}{$\mathrm{T}_{1}$} & \multirow[t]{4}{*}{$\mathrm{I}_{1}$} & 0.9 & 0.7 & 0.5 & 0 & 0 & 0 & 0 & 0 & 0 & 0 & 0.91904 & \multirow[t]{4}{*}{0.905386} \\
\hline & & 0.6 & 0.9 & 0.4 & 0.2 & 0 & 0 & 0 & 0 & 0 & 0 & 0.89047 & \\
\hline & & $\begin{array}{l}0.8 \\
5\end{array}$ & 0.6 & 0.2 & 0.1 & 0 & 0 & 0 & 0 & 0 & 0 & 0.92571 & \\
\hline & & 1 & $\begin{array}{l}0.9 \\
2\end{array}$ & 0.7 & 0.4 & 0 & 0 & 0 & 0 & 0 & 0 & 0.88344 & \\
\hline \multirow[t]{3}{*}{$\mathrm{T}_{2}$} & \multirow{3}{*}{$\begin{array}{l}I_{1} \\
I_{2}\end{array}$} & 0 & 0.1 & 0.7 & 0.9 & 0.2 & 0 & 0 & 0 & 0 & 0 & 0.73684 & \multirow[t]{3}{*}{0.739824} \\
\hline & & 0 & 0 & 0.8 & $\begin{array}{l}0.9 \\
4\end{array}$ & 0.1 & 0 & 0 & 0 & 0 & 0 & 0.73804 & \\
\hline & & 0 & 0.1 & 0.9 & 0.7 & 0.4 & 0 & 0 & 0 & 0 & 0 & 0.73333 & \\
\hline
\end{tabular}




\begin{tabular}{|c|c|c|c|c|c|c|c|c|c|c|c|c|c|}
\hline & $\mathrm{I}_{4}$ & 0 & 0.8 & 0.9 & 0.8 & 0.3 & 0.1 & 0 & 0 & 0 & 0 & 0.76896 & \\
\hline \multirow[t]{4}{*}{$\mathrm{T}_{3}$} & \multirow{4}{*}{$\begin{array}{l}l_{1} \\
I_{2} \\
I_{3} \\
I_{4}\end{array}$} & 0 & 0 & 0 & 0 & 0.3 & 0.8 & 0.4 & 0 & 0 & 0 & 0.49333 & \multirow[t]{4}{*}{0.629573} \\
\hline & & 0 & 0 & 0 & 0.4 & 0.9 & 0.5 & 0 & 0 & 0 & 0 & 0.85555 & \\
\hline & & 0 & 0 & 0 & 0 & 0 & 0.1 & 0.5 & 0.9 & 0.1 & 0 & 0.296875 & \\
\hline & & 0.1 & 0.6 & 0.9 & 0.6 & 0.1 & 0 & 0 & 0 & 0 & 0 & 0.8 & \\
\hline \multirow[t]{4}{*}{$\mathrm{T}_{4}$} & \multirow{4}{*}{$\begin{array}{l}\mathrm{l}_{1} \\
\mathrm{I}_{2} \\
\mathrm{I}_{3} \\
\mathrm{I}_{4}\end{array}$} & 0 & 0 & 0 & 0.9 & 0.5 & 0.1 & 0 & 0 & 0 & 0 & 0.65333 & \multirow[t]{4}{*}{0.424699} \\
\hline & & 0 & 0 & 0 & 0 & 0 & 0.1 & 1 & 0.1 & 0 & 0 & 0.395 & \\
\hline & & 0 & 0 & 0 & 0 & 0 & 0 & 0.7 & 1 & 0.4 & 0 & 0.161904 & \\
\hline & & 0 & 0 & 0 & 0 & 0 & 1 & 0.8 & 0.5 & 0.2 & 0.1 & 0.3832 & \\
\hline
\end{tabular}

Assume that the weights $\left(w_{1}, w_{2}, w_{3}, w_{4}\right)$ of instruction parameter $I_{1}, I_{2}, I_{3}$ and $I_{4}$ are respectively $0.3,0.4,0.2$, 0.1 .

$\mathrm{D}\left(\mathrm{I}_{11}\right)=\frac{0.9 \times \mathrm{H}(\mathrm{E})+0.7 \times \mathrm{H}(\mathrm{VG})+0.5 \times \mathrm{H}(\mathrm{G})}{0.9+0.7+0.5}=\frac{0.9 \times 1+0.7 \times 0.9+0.5 \times 0.8}{2.1}=0.91904$

Similarly, the other calculated degrees of satisfaction are as follows:

$\mathrm{D}\left(\mathrm{I}_{12}\right)=0.89047, \quad \mathrm{D}\left(\mathrm{I}_{13}\right)=0.92571, \quad \mathrm{D}\left(\mathrm{I}_{14}\right)=0.88344, \quad \mathrm{D}\left(\mathrm{I}_{21}\right)=0.73684, \quad \mathrm{D}\left(\mathrm{I}_{22}\right)=0.73804, \quad \mathrm{D}\left(\mathrm{I}_{23}\right)=0.73333$, $\mathrm{D}\left(\mathrm{I}_{24}\right)=0.0 .76896, \quad \mathrm{D}\left(\mathrm{I}_{31}\right)=0.0 .49333, \quad \mathrm{D}\left(\mathrm{I}_{32}\right)=0.8555, \quad \mathrm{D}\left(\mathrm{I}_{33}\right)=0.0 .296875, \quad \mathrm{D}\left(\mathrm{I}_{34}\right)=0.8, \quad \mathrm{D}\left(\mathrm{I}_{41}\right)=0.0 .65333$, $\mathrm{D}\left(\mathrm{I}_{42}\right)=0.395, \mathrm{D}\left(\mathrm{I}_{43}\right)=0.161904, \mathrm{D}\left(\mathrm{I}_{44}\right)=0.3832$.

Degree of satisfaction for topic is calculated as below:

$$
\begin{aligned}
P\left(T_{1}\right)= & \frac{w_{1} \times D\left(I_{11}\right)+w_{2} \times D\left(I_{12}\right)+w_{3} \times D\left(I_{13}\right)+w_{4} \times D\left(I_{14}\right)}{w_{1}+w_{2}+w_{3}+w_{4}} \\
& =0.3 \times 0.91904+0.4 \times 0.89047+0.2 \times 0.92571+0.1 \times 0.88344=0.905386 .
\end{aligned}
$$

1

Similarly, the other degree of satisfaction for the topics are $P\left(T_{2}\right)=0.739824, P\left(T_{3}\right)=0.629573$, $P\left(T_{4}\right)=0.424699$

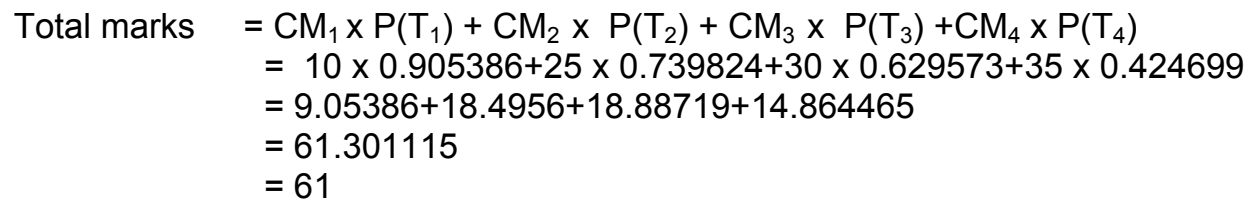

\section{COMPARATIVE ANALYSIS WITH NON-FUZZY APPROACH}

The result obtained from fuzzy evaluation can be compared with non-fuzzy approach. In the non-fuzzy approach Marks in each topic $T_{i}$ is calculated as shown in below table: 
Tab 6: Non-fuzzy performance sheet

\begin{tabular}{|c|c|l|c|c|c|}
\hline $\begin{array}{c}\text { Topic } \\
\text { No. }\end{array}$ & $\begin{array}{c}\text { Instruction } \\
\text { parameter }\end{array}$ & $\begin{array}{c}\text { Maximum } \\
\text { membership } \\
\text { value }\end{array}$ & $\begin{array}{c}\text { Satisfaction } \\
\text { level }\end{array}$ & $\begin{array}{c}\text { Degree of } \\
\text { satisfaction }\end{array}$ & $\begin{array}{c}\text { Non-fuzzy } \\
\text { marks (100 } \\
\text { grade scale) }\end{array}$ \\
\hline & $\mathrm{I}_{1}$ & 0.9 & $\mathrm{E}$ & $91-100 \%$ & 95 \\
$\mathrm{~T}_{1}$ & $\mathrm{I}_{2}$ & 0.9 & $\mathrm{VG}$ & $81 \%-90 \%$ & 85 \\
& $\mathrm{I}_{3}$ & 0.85 & $\mathrm{E}$ & $91-100 \%$ & 95 \\
& $\mathrm{I}_{4}$ & 1 & $\mathrm{E}$ & $91-100 \%$ & 95 \\
\hline & $\mathrm{I}_{1}$ & 0.9 & $\mathrm{MG}$ & $61 \%-70 \%$ & 65 \\
$\mathrm{~T}_{2}$ & $\mathrm{I}_{2}$ & 0.94 & $\mathrm{MG}$ & $61 \%-70 \%$ & 65 \\
& $\mathrm{I}_{3}$ & 0.9 & $\mathrm{G}$ & $71 \%-80 \%$ & 75 \\
& $\mathrm{I}_{4}$ & 0.9 & $\mathrm{G}$ & $71 \%-80 \%$ & 75 \\
\hline & $\mathrm{I}_{1}$ & 0.8 & $\mathrm{MB}$ & $41 \%-50 \%$ & 45 \\
$\mathrm{~T}_{3}$ & $\mathrm{I}_{2}$ & 0.9 & $\mathrm{~F}$ & $51 \%-60 \%$ & 55 \\
& $\mathrm{I}_{3}$ & 0.9 & $\mathrm{VB}$ & $10 \%-24 \%$ & 17 \\
& $\mathrm{I}_{4}$ & 0.9 & $\mathrm{G}$ & $71 \%-80 \%$ & 75 \\
\hline & $\mathrm{I}_{1}$ & 0.9 & $\mathrm{MG}$ & $61 \%-70 \%$ & 65 \\
$\mathrm{~T}_{4}$ & $\mathrm{I}_{2}$ & 1 & $\mathrm{~B}$ & $25 \%-40 \%$ & 32 \\
& $\mathrm{I}_{3}$ & 1 & $\mathrm{VB}$ & $10 \%-24 \%$ & 17 \\
& $\mathrm{I}_{4}$ & 1 & $\mathrm{MB}$ & $41 \%-50 \%$ & 45 \\
\hline
\end{tabular}

Assume that the non fuzzy mark in each instruction parameter is the average of the range of the degree of satisfaction in each instruction parameter.

Non-fuzzy marks in $T_{1}=(95+85+95+95) / 4=92.5$ in 100 grade scale and it's equivalent marks according to total marks to allotted to $T_{1}$ is $92.5 / 10=9.25$. Similarly the other non-fuzzy marks are $T_{2}=17.5, T_{3}=14.4, T_{4}$ $=13.9125$.

$\begin{aligned} \text { Total marks } & =9.25+17.5+14.4+13.9125 \\ & =55.0625 \\ & =55\end{aligned}$

The Fig. 2 shows the graphical representation of fuzzy and non-fuzzy marks of each topic.

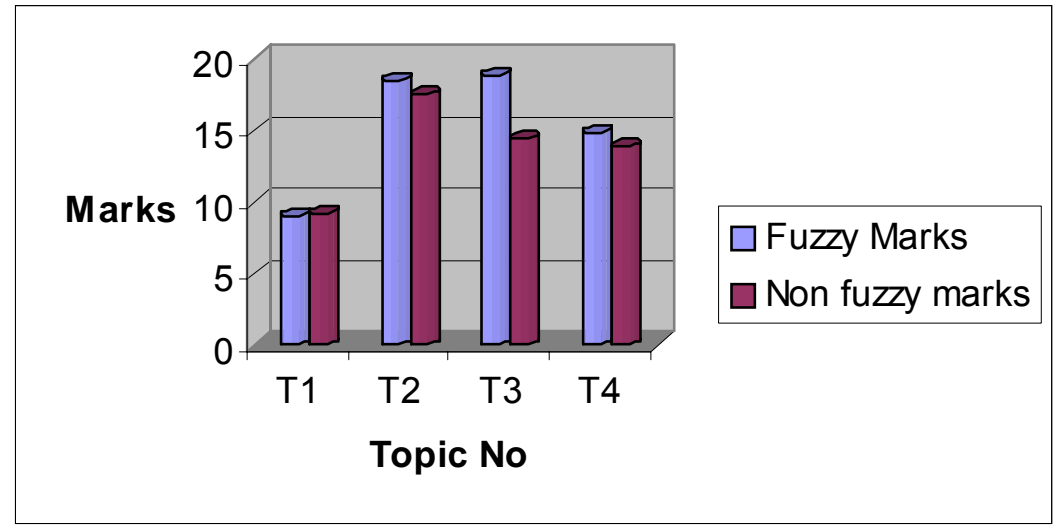


Fig. 2 : Results of Faculty marks in each topic

The Fig. 3 shows the graphical representation of fuzzy and non-fuzzy marks in the subject. Fuzzy marks obtained are more than the non-fuzzy marks. The satisfaction level differs in both the approach where the fuzzy result shows $M G$ (medium good) and non-fuzzy result shows $F$ (Fair) ranking. The fuzzy result is more accurate for performance evaluation than the non-fuzzy method.

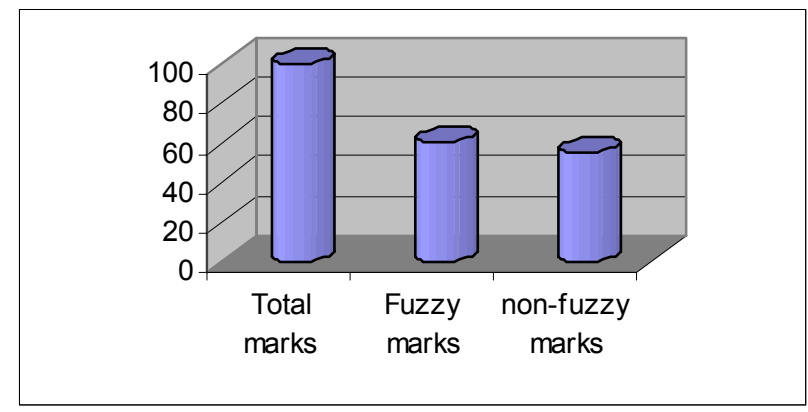

Fig. 3 : Comparative Results of fuzzy and non-fuzzy marks in the subject

\section{CONCLUSION}

In this paper, a model for evaluating faculty performance in the areas of teaching a subject has been presented. The model is based on the premise that faculty performance should be viewed on quality aspect. The discussed method is applied to the evaluation of subject teaching ability based on several instruction parameters. The model is explained with the help of a suitable case study. The comparative performance analysis is presented and the fuzzy performance result is better than non-fuzzy result. The approach chosen can be used for the performance evaluation of a faculty in any department of any university.

\section{REFERENCES}

[1] Jauch L.R., Glueck, W.F., "Evaluation of university professors' research performance", Management Science, Vol. 2, No. 1, pp. 66-75, 1975.

[2] Ellington, H., Ross, G., "Evaluating Teaching Quality throughout a University A Practical Scheme Based on Self-assessment", Quality Assurance in Education, Vol. 2, No. 2, pp. 4-9, 1994.

[3] Sproule, R., "The under determination of instructor performance by data from the student evaluation of teaching", Economics of Education Review 21, pp.287-294, 2002.

[4] Paulsen, M.B., "Evaluating teaching performance", New Directions for Institutional Research, 14, 518, 2002.

[5] Deutsch, S., J., Malmborg, C., J., "Evaluating organizational performance using fuzzy subsets", European Journal of Operational Research, 22(2), 1985, 234-242, 2003.

[6] Hon, C.-C., Guh, Y.- Y., Wang, K.-M., "Fuzzy Multiple Attributes and Multiple Hierarchical Decision Making", Computers Math. Applic., Vol. 32, No. 12, pp. 109-119, 1996.

[7] Earl Cox (1999), "The Fuzzy Systems Handbook: A Practitioner's Guide to Building, Using \& Maintaining Fuzzy Systems".

[8] A. Kaufmann, M.M. Gupta, "Fuzzy Mathematical Modelling in Engineering and Management Science", North-Holland, Amsterdam, 1988. 